\title{
Risk Factors for Extraintestinal Manifestations in Inflammatory Bowel Diseases - Data from the Romanian National Registry
}

\author{
Ana-Maria Sîngeap ${ }^{1}$, Irina Gîrleanu ${ }^{1}$, Mircea Diculescu ${ }^{2}$, Liana Gheorghe ${ }^{2}$, Maria Ciocîrlan² $^{2}$, Cristian Gheorghe ${ }^{2}$, \\ Adrian Costache ${ }^{3}$, Alina Tanțău $u^{4}$, Roxana Zaharie ${ }^{5}$, Adrian Goldiș ${ }^{6}$, Dan Gheonea ${ }^{7}$, Daniela Dobru ${ }^{8}$, Eugen Dumitru ${ }^{9}$, \\ Cristina Cijevschi Prelipcean ${ }^{1}$, Georgiana-Emmanuela Gîlcă-Blanariư ${ }^{1}$, Mihaela Moscalu ${ }^{10}$, Carol Stanciu ${ }^{1}$, Anca Trifan ${ }^{1}$
}

1) Grigore T. Popa UMF, Inst.

of Gastroenterol. and Hepatol., Emergency County Hospital Saint Spiridon, Iasi; 2) Carol Davila UMF, Digestive Diseases and Liver Transplantation Center, Fundeni Clinical Inst., Bucharest; 3) Carol Davila UMF, Dr. I. Cantacuzino Clinical Hospital, Bucharest; 4) Iuliu Hațieganu UMF, $4^{\text {th }}$ Medical Clinic, Cluj- Napoca;

5) Iuliu Hatieganu UMF,

Regional Inst. of Gastroenterol. and Hepatol., Cluj-Napoca; 6) Victor Babeș UMF, Municipal Emergency Hospital, Dept. of Gastroenterol. and Hepatol., Timișoara; 7) UMF Craiova, Research Center of Gastroenterol. and Hepatol., Craiova; 8)UMF Tg. Mures, Emergency County Hospital, Dept. of Gastroenterol.,

Târgu-Mureș; 9) Faculty of Medicine, Ovidius University of Constanța, Emergency County Hospital, Dept. of Gastroenterol, Constanța; 10) Dept. of Preventive Medicine and Interdisciplinarity, Grigore T. Popa UMF, Iași; Romania

\section{Address for correspondence: \\ Mihaela Moscalu, \\ Dept. of Preventive Medicine and Interdisciplinarity, Grigore T. Popa UMF, Iași, Romania moscalu.mihaela@gmail.com}

Received: 04.05.2021 Accepted: 22.06 .2021

\section{ABSTRACT}

Background \& Aims: Identifying the risk factors for extraintestinal manifestations (EIMs) in inflammatory bowel diseases (IBD) may optimize the therapeutic decision. We aimed to assess the prevalence of EIMs in IBD patients in Romania and to determine the risk factors.

Methods: We analyzed 2,626 patients registered in the Romanian IBD Prospect National Registry. We performed a descriptive cross-sectional study to assess the point prevalence of EIMs, calculating global prevalence and analyzing the different types of EIMs and their respective frequencies were carried out. Demographic and clinical risk factors were researched as possible predictors for EIMs development, based on the results of the univariate and multivariate logistic regression analysis.

Results: The overall point prevalence of EIMs was 16.3\%. A significantly higher frequency of EIMs in Crohn's disease (CD) was noted in comparison to ulcerative colitis (UC) and IBD unclassified (IBDU) (23.2\% vs $11.3 \%$ and $16.3 \%$, respectively, $\mathrm{p}<0.001)$. The most frequent type of EIM was peripheral arthropathy $(8.3 \%)$, significantly associated with $\mathrm{CD}(\mathrm{p}<0.001)$. Univariate analysis highlighted the significant independent common predictive risk factors for EIMs, in both CD and UC patients: female gender, patient's urban area of origin, anemia, hypoalbuminemia, and high level of C-reactive protein (CRP), while significant independent IBD phenotype-related risk factors were ileocolonic location and concomitant involvement of upper gastrointestinal tract for $\mathrm{CD}$, non-smoker status and both moderate and severe disease activity for UC $(\mathrm{p}<0.05)$. Multivariate analysis determined that female CD patients with moderate or severe disease activity, with other than isolated ileal disease, and female UC patients with moderate or severe extensive colitis are the most likely to develop EIMs.

Conclusions: IBD patients are experiencing EIMs in a large proportion, with higher rates for CD. As EIMs negatively affect patient outcomes, foreseeing the risk by identifying independent and associated predictive factors could be a first step to optimal work-up and treatment

Key words: inflammatory bowel disease - Crohn's disease - ulcerative colitis - extraintestinal manifestations - prevalence - risk factors.

Abbreviations: CD: Crohn's disease; CRP: C-reactive protein; EIMs: extraintestinal manifestations; IBD: inflammatory bowel disease; IBDU: IBD unclassified; UC: ulcerative colitis; UTI: urinary tract infection.

\section{INTRODUCTION}

Although inflammatory bowel diseases (IBD) have been known for more than a century, there are still several pending issues, regarding comprehension of the pathogenesis, clinical presentation and evolution, as well as the optimal and timely treatment choice. The clinical picture of ulcerative colitis (UC), Crohn's disease (CD) and IBD unclassified (IBDU) is heterogeneous, with particular aspects concerning disease extension and behavior, miscellaneous evolution patterns, and, last but not least, a variable potential for extraintestinal involvement.

Globally, approximately one-third of patients with IBD develop extraintestinal manifestations (EIMs). Previous studies shown that $6-47 \%$ of IBD patients experience EIMs, reporting the different frequencies according to the study population, study type, length of follow-up, and definition criteria [1-4]. There appears to be an increase of cumulative risk for EIMs 
starting from the time of diagnosis, especially for CD patients $[5,6]$, and throughout the disease course, around a quarter of patients may experience multiple EIMs [7].

The clinical spectrum and severity of EIMs vary, ranging from mild evanescent signs or symptoms to truly debilitating complications. EIMs are classified into two types: immunemediated conditions, which share presumed immunological pathogenesis with the bowel disease - joint involvement, skin manifestations, ophthalmologic disorders, amyloidosis, and sclerosing cholangitis, and nonimmune-mediated conditions, determined by metabolic or other structural processes secondary to the bowel disease - cholelithiasis, nephrolithiasis, obstructive uropathy, osteopathy. Anemia may also be considered an EIM, but in most cases, it has complex pathogenesis, involving inflammation, malabsorption, and bleeding.

Regardless of their severity, if present, EIMs may affect the patients' quality of life. Furthermore, according to their type and impact on the patient's medical condition, EIMs may require additional healthcare resources.

Because there may be certain categories of patients more likely to develop EIMs, a complete characterization of patients' susceptibility profile and the identification of risk factors for developing EIMs could improve early recognition and therapeutic strategy.

The aim of our study was to assess the frequency and types of EIMs in Romanian patients with IBD. Our secondary objective was to identify demographical and clinical risk factors for developing EIMs.

\section{METHODS}

Our study included all the patients recorded in the Romanian IBD Prospect National Registry, a database established more than a decade ago and continuously updated, including patients from thirteen Romanian tertiary centers to cover areas across the country, belonging to eight university medical centers. These tertiary centers have been enrolling IBD patients with a confirmed diagnosis, based on clinical, laboratory, endoscopic, imaging, and histological criteria. All demographic, history, clinical, and paraclinical parameters were recorded at baseline and during follow-up and every new event was noted in a dynamic, real-time manner. All patients have signed the informed consent before registration. The study protocol followed the principles outlined in the Declaration of Helsinki regarding research involving human subjects and was approved by the local Ethics Committee.

We performed a descriptive cross-sectional study, assessing the point prevalence of EIMs. The global prevalence of EIMs was calculated, together with the prevalence among different categories of patients, according to IBD phenotype, demographic features, disease pattern, extension, and severity. Consecutively, the risk factors for EIMs were assessed. EIMs were noted as "present" or "absent" for each patient. When "present", the specific type of EIM was recorded: peripheral arthropathy, axial arthropathies - ankylosing spondylitis/ sacroiliitis, erythema nodosum, pyoderma gangrenosum, uveitis, episcleritis, pericholangitis, primary sclerosing cholangitis, nephrolithiasis, obstructive uropathy, recurrent urinary tract infections (UTI), and amyloidosis.
Amid demographic characteristics, patient gender, age, and place of origin were recorded. Tobacco use was also considered, the patient being labeled as smoker, non-smoker or ex-smoker. IBD family history was assessed. IBD phenotype was classified into three categories: UC, CD, and IBDU. Crohn's disease pattern was classified according to Montreal classification, comprising: age at onset (A1: below 16 years, A2: between 17 and 40 years, A3: above 40 years), disease location (L1: ileal, L2: colonic, L3: ileocolonic, L4: upper gastrointestinal tract) and disease behavior (B1: nonstricturing, nonpenetrating, B2: stricturing, B3: penetrating, p: perianal disease) [8]. The extent of UC was defined as proctitis (E1), left-sided colitis (E2), or extended colitis, including pancolitis (E3) [9]. Crohn's disease severity was assessed by calculating Crohn's Disease Activity Index (CDAI) [10], while UC severity was graded using the Mayo score [11]; IBDU cases were classified similarly to those of UC.

The statistical analysis was performed using STATA 16.1 (StataCorp LLC, Texas, USA). Depending on the variables distribution, the data were presented as mean and standard deviation or median and quartile. The Pearson Chi-square test was used to evaluate EIMs associations based on diagnosis (CD, UC, IBDU). Possible predictors for EIMs were searched based on the results of the univariate and multivariate logistic regression analysis. The statistical significance level of $\mathrm{p}<0.05$ was considered as the reference threshold.

\section{RESULTS}

\section{Patients' Characteristics}

In total, 2,626 IBD patients were included, namely 1,099 CD patients (41.9\%), 1,484 UC patients (56.5\%), and 43 with IBDU (1.6\%). The demographic and clinical characteristics of the study patients are shown in Table I. We have noted a slight predominance for the male gender in $\mathrm{UC}$, and for the female gender in CD. Mean age was slightly higher in UC patients than in CD or IBDU patients. Patients' place of origin was predominantly rural for all IBD phenotypes, with a rural/ urban ratio of 2.8 in all IBD patients. Few patients $(2.6 \%)$ had a familial history of IBD. The predominant location of CD was ileocolonic (L3) (43.7\%), followed by colonic and ileal sites; upper gastrointestinal tract was associated in $5.1 \%$ of cases; no isolated upper gastrointestinal disease was present. The predominant behavior of CD was inflammatory (nonstricturing, nonpenetrating), with more than $50 \%$ of cases, while approximately $11 \%$ of cases associated perianal disease. The extent of UC was predominantly E2. Regarding IBD severity, at the time of the analysis, moderate activity was predominant for CD and UC, followed by mild activity, remission, and severe activity.

\section{Prevalence and Types of EIMs}

Overall, 429 patients presented at least one EIM at the time of the study, resulting in a point prevalence of $16.3 \%$. Phenotype analysis showed a significantly higher frequency of EIMs in CD compared to UC and IBDU (23.2\% vs $11.3 \%$ and $16.3 \%, \mathrm{p}<0.001)$.

Table II shows the overall prevalence of EIMs as well as IBD phenotype-related point prevalence of each type of EIM. 
Table I. Patients characteristics

\begin{tabular}{|c|c|c|c|c|}
\hline & $\begin{array}{c}\text { All IBD patients } \\
n=2,626\end{array}$ & $\begin{array}{c}\mathrm{CD} \\
\mathrm{n}=1,099(41.9 \%)\end{array}$ & $\begin{array}{c}\text { UC } \\
n=1,484(56.5 \%)\end{array}$ & $\begin{array}{c}\text { IBDU } \\
n=43(1.6 \%)\end{array}$ \\
\hline \multicolumn{5}{|l|}{ Gender ratio, $\mathrm{n}(\%)$} \\
\hline Women/men & $\begin{array}{l}1,245 / 1,381 \\
(47.4 / 52.6)\end{array}$ & $\begin{array}{c}563 / 536 \\
(51.2 / 48.8 \%)\end{array}$ & $\begin{array}{c}657 / 827 \\
(44.3 / 55.7)\end{array}$ & $\begin{array}{c}25 / 18 \\
(58.1 / 41.9)\end{array}$ \\
\hline \multicolumn{5}{|l|}{ Age, years } \\
\hline $\begin{array}{l}\text { Mean+SD } \\
\text { Median }(\mathrm{Q} 1 ; \mathrm{Q} 3)\end{array}$ & $\begin{array}{c}43.8 \pm 15.442 \\
\quad(31 ; 56)\end{array}$ & $\begin{array}{c}41.6 \pm 14.939 \\
(29 ; 53)\end{array}$ & $\begin{array}{l}45.5 \pm 15.444 \\
\quad(33 ; 57)\end{array}$ & $\begin{array}{c}43.8 \pm 17.739 \\
(28 ; 62)\end{array}$ \\
\hline \multicolumn{5}{|l|}{ Patient's place of origin, $n(\%)$} \\
\hline Urban/rural, n (\%) & $\begin{array}{c}691 / 1,935 \\
(26.3 / 73.7)\end{array}$ & $\begin{array}{c}245 / 854 \\
(22.3 / 77.7)\end{array}$ & $\begin{array}{c}428 / 1,056 \\
(28.8 / 71.2)\end{array}$ & $\begin{array}{c}18 / 25 \\
(41.9 / 58.1)\end{array}$ \\
\hline \multicolumn{5}{|l|}{ Smoking status, $\mathrm{n}(\%)$} \\
\hline Non-smoker/Ex-smoker/Smoker & $\begin{array}{c}1,477 / 688 / 461 \\
(56.2 / 26.2 / 17.6)\end{array}$ & $\begin{array}{c}571 / 273 / 255 \\
(52 / 24.8 / 23.2)\end{array}$ & $\begin{array}{c}883 / 406 / 195 \\
(59.5 / 27.4 / 13.1)\end{array}$ & $\begin{array}{c}23 / 9 / 11 \\
(53.5 / 20.9 / 25.6)\end{array}$ \\
\hline Familial history of IBD, $\mathrm{n}(\%)$ & $69(2.6)$ & $33(3)$ & $34(2.3)$ & $2(4.6)$ \\
\hline \multicolumn{5}{|l|}{ Age group at diagnosis for CD, $\mathrm{n}(\%)$} \\
\hline $\begin{array}{l}\text { A1 }<16 \text { years } \\
\text { A2 }=17-40 \text { years } \\
\text { A3 }>40 \text { years }\end{array}$ & - & $\begin{array}{c}39(3.6) \\
708(64.4) \\
352(32)\end{array}$ & - & - \\
\hline \multicolumn{5}{|l|}{ Location of CD, $\mathrm{n}(\%)$} \\
\hline $\begin{array}{l}\text { L1 } \\
\text { L2 } \\
\text { L3 } \\
\text { Concomitant L4 }\end{array}$ & - & $\begin{array}{c}222(20.2) \\
397(36.1) \\
480(43.7) \\
56(5.1)\end{array}$ & - & - \\
\hline \multicolumn{5}{|l|}{ Behavior of $\mathrm{CD}, \mathrm{n}(\%)$} \\
\hline $\begin{array}{l}\text { B1 } \\
\text { B2 } \\
\text { B3 }\end{array}$ & - & $\begin{array}{l}711(64.7) \\
250(22.8) \\
138(12.6)\end{array}$ & - & - \\
\hline Perianal disease, $\mathrm{n}(\%)$ & - & $124(11.3)$ & - & - \\
\hline \multicolumn{5}{|l|}{ Extent of UC, n (\%) } \\
\hline $\begin{array}{l}\text { E1 } \\
\text { E2 } \\
\text { E3 }\end{array}$ & - & - & $\begin{array}{l}241(16.2) \\
760(51.2) \\
483(32.6)\end{array}$ & - \\
\hline \multicolumn{5}{|l|}{ Activity of IBD, n (\%) } \\
\hline $\begin{array}{l}\text { Remission } \\
\text { Mild activity } \\
\text { Moderate activity } \\
\text { Severe activity }\end{array}$ & - & $\begin{array}{c}228(20.8) \\
306(27.8) \\
415(37.8) \\
150(13.6\end{array}$ & $\begin{array}{l}263(17.7) \\
435(29.3) \\
565(38.1) \\
221(14.9\end{array}$ & $\begin{array}{c}3(7) \\
18(41.8) \\
15(34.9) \\
7(16.3)\end{array}$ \\
\hline Extraintestinal manifestations, $\mathrm{n}(\%)$ & $429(16.3)$ & $255(23.2)$ & $167(11.2)$ & $7(16.3)$ \\
\hline
\end{tabular}

B1: nonstricturing, nonpenetrating; B2: stricturing; B3: penetrating; CD: Crohn's disease; SD: standard deviation; E1: proctitis; E2: left side colitis; E3: extended colitis; IBD: inflammatory bowel disease; IBDU: IBD unclassified; L1: ileal; L2: ileocolonic; L4: upper gastrointestinal tract; Q1: first quartile; Q3: third quartile; UC: ulcerative colitis.

The most frequent EIM was peripheral arthropathy (8.3\%), significantly associated with CD (12.4\% of cases, $\mathrm{p}<0.001)$. Axial arthropathies were encountered in $3.9 \%$ of IBD patients, significantly more frequent in CD compared to UC $(5.8 \%$ vs $2.4 \%, \mathrm{p}<0.001)$. Among dermatological manifestations, erythema nodosum had a significantly increased frequency in CD and IBDU compared to UC $(2.7 \%$ and $2.3 \%$, vs $0.4 \%, \mathrm{p}<0.001$ ), while pyoderma gangrenosum was less frequent and did not show a particular predilection for one IBD phenotype.

Low prevalence and no significant association with IBD phenotype were found for pericholangitis $(0.08 \%)$, primary sclerosing cholangitis $(0.8 \%)$, renal stones $(1.9 \%)$, recurrent UTI (1.5\%), and amyloidosis (0.04\%).
However, certain EIMs with low prevalence were significantly associated with IBD phenotype. Thus, ophthalmological EIMs (uveitis and episcleritis) had a global frequency of $1.03 \%$, significantly higher in IBDU compared to CD or UC $(\mathrm{p}<0.001)$, while ureterohydronephrosis (overall frequency $0.3 \%$ ) had an increased prevalence in $\mathrm{CD}$ patients $(0.6 \%)$ compared to UC $(0.07 \%)(p=0.025)$.

Multiple EIMs were noted in $2.9 \%$ of IBD patients. The number of concomitant EIMs differed significantly according to IBD phenotype (Table II). Thus, one single EIM occurred significantly more frequently in CD patients (18.3\%) compared to UC $(9.9 \%)$ and IBDU $(6.9 \%)$ patients $(\mathrm{p}<0.001)$, while the concomitance of two distinct EIMs was recorded with significantly higher frequency in IBDU patients $(9.3 \%$, 
Table II. Prevalence of extraintestinal manifestations (EIMs) according to inflammatory bowel disease (IBD) phenotype

\begin{tabular}{lcccccc}
\hline EIM & All IBD patients & $\mathrm{CD}(\mathrm{n}, \%)$ & $\mathrm{UC}(\mathrm{n}, \%)$ & $\mathrm{IBDU}(\mathrm{n}, \%)$ & Statistic Test & $\mathrm{p}^{\dagger}$ \\
\hline All EIMs & $429(16.3)$ & $255(23.2)$ & $167(11.3)$ & $7(16.3)$ & 65.96 & $<0.001^{*}$ \\
Peripheral arthropathies & $218(8.3)$ & $136(12.4)$ & $78(5.3)$ & $4(9.3)$ & 42.09 & $<0.001^{*}$ \\
Axial arthropathies & $101(3.9)$ & $64(5.8)$ & $35(2.4)$ & $2(4.7)$ & 20.57 & $<0.001^{*}$ \\
Erythema nodosum & $37(1.4)$ & $30(2.7)$ & $6(0.4)$ & $1(2.3)$ & 24.84 & $<0.001^{*}$ \\
Pyoderma gangrenosum & $17(0.7)$ & $10(0.9)$ & $7(0.5)$ & $0(0)$ & 2.17 & 0.338 \\
Uveitis/Episcleritis & $27(1.03)$ & $19(1.7)$ & $6(0.4)$ & $2(4.7)$ & 16.52 & $<0.001^{*}$ \\
Pericholangitis & $2(0.08)$ & $2(0.2)$ & $0(0)$ & $0(0)$ & 3.48 & 0.175 \\
Primary sclerosing cholangitis & $21(0.8)$ & $8(0.7)$ & $13(0.9)$ & $0(0)$ & 0.52 & 0.768 \\
Renal stones & $50(1.9)$ & $24(2.2)$ & $25(1.7)$ & $1(2.3)$ & 0.83 & 0.643 \\
Ureterohydronephrosis & $8(0.3)$ & $7(0.6)$ & $1(0.07)$ & $0(0)$ & 7.32 & $0.025^{*}$ \\
Recurrent UTI & $38(1.5)$ & $19(1.7)$ & $18(1.2)$ & $1(2.3)$ & 1.41 & 0.492 \\
Amyloidosis & $1(0.04)$ & $1(0.1)$ & $0(0)$ & $0(0)$ & 1.74 & 0.418 \\
Multiple extraintestinal manifestations & & & & & \\
None, $\mathrm{n}$ (\%) & $2,197(83.7)$ & $844(76.8)$ & $1,317(88.8)$ & $36(83.7)$ & & \\
One EIM & $351(13.4)$ & $201(18.3)$ & $147(9.9)$ & $3(6.9)$ & & \\
Two EIMs & $67(2.6)$ & $44(4)$ & $19(1.3)$ & $4(9.3)$ & 84.51 & $<0.001^{*}$ \\
Three EIMs & $9(0.3)$ & $9(0.8)$ & $0(0)$ & $0(0)$ & & \\
Four EIMs & $2(0.08)$ & $1(0.09)$ & $1(0.07)$ & $0(0)$ & & \\
\hline
\end{tabular}

${ }^{\dagger}$ Pearson Chi-square test; ${ }^{\star}$ Marked effects are significant at $\mathrm{p}<0.05$; UTI: urinary tract infections. For other abbreviations see Table I.

$\mathrm{p}<0.001)$. We identified nine cases with three simultaneous EIMs, corresponding to $0.34 \%$ of all IBD patients and two cases with four concomitant EIMs, corresponding to $0.08 \%$ of all IBD patients. The occurrence of more than two EIMs was identified especially among CD patients.

\section{Risk Factors for EIMs}

Logistic regression univariate and multivariate analysis were performed, according to the disease phenotype, in order to identify predictive factors for EIMs in IBD patients.

\section{Univariate Analyses (Table III)}

Regarding CD patients, we found a significant correlation between female gender and the presence of EIMs $(\mathrm{OR}=1.56$, 95\%CI: 1.18-2.07, $\mathrm{p}=0.002$ ). The patient's urban area of origin was also significantly correlated with the development of EIMs $(\mathrm{OR}=1.49,95 \% \mathrm{CI}: 1.1-2.04, \mathrm{p}=0.042)$. Among biochemical markers, elevated C-reactive protein (CRP) levels ( $\mathrm{OR}=1.37$, 95\%CI: 1.13-2.19, $\mathrm{p}=0.035)$, low hemoglobin $(\mathrm{OR}=1.41,95 \% \mathrm{CI}$ : $1.22-2.48, \mathrm{p}=0.021)$ and low serum albumin levels $(\mathrm{OR}=1.53$, 95\%CI: 1.39-3.99, $\mathrm{p}=0.016)$ were predictive factors for EIMs. According to $\mathrm{CD}$ location, $\mathrm{L} 3(\mathrm{OR}=2.87,95 \% \mathrm{CI}$ : $1.59-4.55$, $\mathrm{p}=0.032$ ), and L4 significantly increased the risk for EIMs development (OR=3.54, 95\%CI: 2.87-5.64, $\mathrm{p}=0.021)$. Though no significant correlation was found between age at diagnosis and the presence of EIMs, a predilection for EIMs occurrence was identified in patients with age at diagnosis between 17 and 40 years $(64.4 \%$ EIMs frequency), compared to those aged more than 40 years at the time of diagnosis (32\% EIMs frequency). CD behavior or the presence of perianal involvement did not appear to influence the risk of EIMs. There was no correlation between family history of IBD, smoking status, or CD activity, and the presence of EIMs.
For UC patients, the predictive factors for developing EIMs were female gender $(\mathrm{OR}=1.56,95 \% \mathrm{CI}: 1.13-2.15, \mathrm{p}=0.006)$, patient's urban area of origin $(\mathrm{OR}=1.52,95 \% \mathrm{CI}$ : $1.03-2.23$, $\mathrm{p}=0.031)$, non-smoker status (OR=1.7, 95\%CI: $1.11-2.43$, $\mathrm{p}=0.027)$ as well as elevated CRP levels $(\mathrm{OR}=2.27,95 \% \mathrm{CI}$ : 1.91-5.74, $\mathrm{p}=0.022)$, low hemoglobin $(\mathrm{OR}=1.34,95 \% \mathrm{CI}$ : $1.09-1.89, \mathrm{p}=0.029)$ and low serum albumin $(\mathrm{OR}=1.42$, 95\%CI: 1.29-2.57, $\mathrm{p}=0.045)$ levels. Both moderate $(\mathrm{OR}=1.65$, 95\%CI: $1.41-3.01, \mathrm{p}=0.032)$ and severe (OR=2.3, 95\%CI: 1.81 $3.13, \mathrm{p}=0.025$ ) disease activity were found to be significant risk factors for EIMs development compared to remission; in severe UC patients the frequency of EIMs was $18.1 \%$. Extensive colitis (E3 extension type) was found to significantly increase the risk of EIMs development compared to proctitis (E1 extension type) (EIM's frequency $15.9 \%$ and $7.05 \%$, respectively, $\mathrm{p}=0.001$ ).

In IBDU, male gender, patient's urban area of origin, as well as high CRP levels, low hemoglobin, and low albumin levels were predictors for EIMs.

\section{Multivariate Analyses}

For $\mathrm{CD}$ patients, female gender $(\mathrm{OR}=3.62,95 \% \mathrm{CI}: 1.2-2.3$, $\mathrm{p}=0.002)$, moderate $(\mathrm{OR}=1.84,95 \% \mathrm{CI}: 1.57-2.13, \mathrm{p}=0.041)$ or severe $(O R=1.95,95 \% C I: 1.62-2.24, p=0.037)$ disease activity and any location other than L1 $(\mathrm{p}<0.05)$ acted as associated risk factors for EIMs (Table IV), while for UC patients the risk was significantly increased by the association between female gender $(\mathrm{OR}=2.64,95 \% \mathrm{CI}$ : 1.37-5.08, $\mathrm{p}=0.004)$, moderate $(\mathrm{OR}=2.9,95 \% \mathrm{CI} 1.3-2.8, \mathrm{p}=0.011)$ or severe $(\mathrm{OR}=2.54 ; 95 \% \mathrm{CI}$ : 1.34-2.85, $\mathrm{p}=0.008)$ disease activity and $\mathrm{E} 3$ extension type (pancolitis) (OR=3.3, 95\%CI: 1.28-4.13, $\mathrm{p}=0.005)$, as shown in Table V. 
Table III. Predictive factors for EIMs in IBD patients - univariate analysis

\begin{tabular}{|c|c|c|c|c|c|}
\hline \multirow[t]{2}{*}{ Variable } & \multirow{2}{*}{$\begin{array}{l}\text { Odd ratio } \\
\operatorname{Exp}(\beta)\end{array}$} & \multicolumn{2}{|c|}{ 95\% CI for $\operatorname{Exp}(\mathrm{B})$} & \multirow[t]{2}{*}{ SE } & \multirow[t]{2}{*}{$\mathrm{p}$} \\
\hline & & Lower & Upper & & \\
\hline \multicolumn{6}{|l|}{ Crohn's disease } \\
\hline \multicolumn{6}{|l|}{ Gender } \\
\hline \multicolumn{6}{|l|}{ Gender } \\
\hline Male & Reference & & & & \\
\hline Female & 1.57 & 1.18 & 2.07 & 0.042 & $0.002^{*}$ \\
\hline Age & 1.0 & 0.99 & 1.01 & 0.005 & 0.726 \\
\hline \multicolumn{6}{|c|}{ Age group at diagnosis (for CD) } \\
\hline $\mathrm{A} 1<16$ years & 1.19 & 0.56 & 2.55 & 0.188 & 0.652 \\
\hline $\begin{array}{l}\text { A2 }=17-40 \text { years } \\
\text { A3 }>40 \text { years }\end{array}$ & $\begin{array}{c}1.19 \\
\text { Reference }\end{array}$ & 0.87 & 1.60 & 0.154 & 0.266 \\
\hline Family history of IBD & 1.21 & 0.52 & 2.83 & 0.032 & 0.650 \\
\hline \multicolumn{6}{|l|}{ Place of origin } \\
\hline $\begin{array}{l}\text { Rural } \\
\text { Urban }\end{array}$ & $\begin{array}{l}\text { Reference } \\
1.49\end{array}$ & 1.11 & 2.04 & 0.178 & $0.042^{*}$ \\
\hline Smoking & & & & & 0.417 \\
\hline Non-smoker & Reference & & & & \\
\hline Ex-smoker & 1.25 & 0.89 & 1.73 & 0.168 & 0.188 \\
\hline Smoker & 1.06 & 0.74 & 1.49 & 0.176 & 0.750 \\
\hline \multicolumn{6}{|l|}{ Active disease } \\
\hline Remission & Reference & & & & \\
\hline Mild activity & 1.41 & 0.93 & 2.14 & 0.212 & 0.101 \\
\hline Moderate activity & 1.45 & 0.97 & 2.14 & 0.200 & 0.064 \\
\hline Severe activity & 1.33 & 0.81 & 2.18 & 0.252 & 0.256 \\
\hline Elevated CRP & 1.38 & 1.13 & 2.19 & 0.117 & $0.035^{*}$ \\
\hline $\mathrm{Hb}$ & 1.41 & 1.22 & 2.48 & 0.149 & $0.021^{*}$ \\
\hline Serum albumin level & 1.53 & 1.39 & 3.99 & 0.205 & $0.016^{*}$ \\
\hline \multicolumn{6}{|l|}{ Location of CD } \\
\hline $\mathrm{L} 1$ & Reference & & & & \\
\hline $\mathrm{L} 2$ & 0.98 & 0.65 & 2.87 & 0.213 & 0.890 \\
\hline L3 & 2.87 & 1.59 & 4.55 & 0.202 & $0.032^{*}$ \\
\hline Concomitant L4 & 3.54 & 2.87 & 5.64 & 0.183 & $0.021^{*}$ \\
\hline \multicolumn{6}{|l|}{ Behavior of CD } \\
\hline B1 & Reference & & & & \\
\hline B2 & 1.20 & 0.86 & 1.67 & 0.168 & 0.274 \\
\hline B3 & 1.20 & 0.79 & 1.82 & 0.212 & 0.383 \\
\hline Perianal disease & 1.02 & 0.66 & 1.58 & 0.022 & 0.918 \\
\hline \multicolumn{6}{|l|}{ Ulcerative colitis } \\
\hline \multicolumn{6}{|l|}{ Gender } \\
\hline $\begin{array}{l}\text { Male } \\
\text { Female }\end{array}$ & $\begin{array}{l}\text { Reference } \\
1.56\end{array}$ & 1.13 & 2.15 & 0.164 & $0.006^{*}$ \\
\hline Age & 1.01 & 0.99 & 1.01 & 0.005 & 0.928 \\
\hline Family history of IBD & 1.34 & 0.51 & 3.51 & 0.191 & 0.549 \\
\hline \multicolumn{6}{|l|}{ Place of origin } \\
\hline $\begin{array}{l}\text { Rural } \\
\text { Urban }\end{array}$ & $\begin{array}{c}\text { Reference } \\
1.52\end{array}$ & 1.03 & 2.23 & 0.195 & $0.031^{*}$ \\
\hline \multicolumn{6}{|l|}{ Smoking } \\
\hline Smoker & Reference & & & & \\
\hline Ex-smoker & 1.52 & 0.98 & 3.14 & 0.196 & 0.058 \\
\hline Non-smoker & 1.71 & 1.11 & 2.43 & 0.267 & $0.027^{*}$ \\
\hline
\end{tabular}




\begin{tabular}{|c|c|c|c|c|c|}
\hline \multicolumn{6}{|l|}{ Table III (continued) } \\
\hline \multicolumn{6}{|l|}{ Disease activity } \\
\hline Remission & Reference & & & & \\
\hline Mild activity & 0.53 & 0.33 & 0.86 & 0.247 & $0.011^{*}$ \\
\hline Moderate activity & 1.65 & 1.42 & 3.01 & 0.225 & $0.032^{*}$ \\
\hline Severe activity & 2.31 & 1.81 & 3.12 & 0.048 & $0.025^{*}$ \\
\hline Elevated CRP & 2.27 & 1.91 & 5.73 & 0.272 & $0.022^{*}$ \\
\hline $\mathrm{Hb}$ & 1.34 & 1.09 & 1.89 & 0.175 & $0.029^{*}$ \\
\hline Serum albumin level & 1.43 & 1.29 & 2.57 & 0.145 & $0.045^{*}$ \\
\hline \multicolumn{6}{|l|}{ Extent } \\
\hline E1 & Reference & & & & \\
\hline E2 & 1.46 & 0.85 & 2.53 & 0.279 & 0.172 \\
\hline E3 & 2.50 & 1.44 & 4.33 & 0.281 & $0.001^{*}$ \\
\hline \multicolumn{6}{|c|}{ Inflammatory bowel diseases unclassified } \\
\hline \multicolumn{6}{|l|}{ Gender } \\
\hline Female & Reference & & & & \\
\hline Male & 2.09 & 1.40 & 5.80 & 0.237 & $0.037^{*}$ \\
\hline Age & 1.01 & 0.96 & 1.05 & 0.024 & 0.726 \\
\hline Family history of IBD & 1.10 & 0.97 & 1.98 & 0.722 & 0.939 \\
\hline \multicolumn{6}{|l|}{ Place of origin } \\
\hline $\begin{array}{l}\text { Rural } \\
\text { Urban }\end{array}$ & $\begin{array}{c}\text { Reference } \\
5.37\end{array}$ & 1.58 & 9.22 & 0.131 & $0.013^{*}$ \\
\hline \multicolumn{6}{|l|}{ Smoking } \\
\hline Non-smoker & Reference & & & & \\
\hline Ex-smoker & 0.59 & 0.05 & 6.17 & 0.195 & 0.663 \\
\hline Smoker & 1.06 & 0.16 & 6.87 & 0.256 & 0.955 \\
\hline \multicolumn{6}{|l|}{ Disease activity } \\
\hline Remission & Reference & & & & \\
\hline Mild activity & 1.15 & 0.68 & 2.67 & 0.101 & 0.921 \\
\hline Moderate activity & 1.38 & 0.35 & 3.88 & 0.032 & 0.864 \\
\hline Severe activity & 1.01 & 0.21 & 4.97 & 0.211 & 0.986 \\
\hline Elevated CRP & 1.44 & 1.13 & 1.78 & 0.229 & $0.036^{*}$ \\
\hline $\mathrm{Hb}$ & 1.31 & 1.22 & 7.56 & 0.296 & $0.005^{*}$ \\
\hline Serum albumin level & 1.37 & 1.19 & 9.64 & 0.257 & $0.014^{*}$ \\
\hline
\end{tabular}

${ }^{*}$ Marked effects are significant at $\mathrm{p}<0.05$; CI: confidence interval; SE: standard error; CD: Crohn's disease; IBD: inflammatory bowel disease; CRP: C-reactive protein; L1: Ileal; L2: Ileocolonic; L4: Upper gastrointestinal tract; B1: Nonstricturing, nonpenetrating; B2: Stricturing; B3: Penetrating; E1: Proctitis; E2: Left side colitis; E3: Extended colitis; UC: Ulcerative colitis; IBDU: Inflammatory bowel disease unclassified.

Regarding IBDU patients, due to the low number of cases, only five variables could be included in the multivariate analysis; among them, patient's urban area of origin $(\mathrm{OR}=4.81$, 95\%CI: $1.48-7.52, \mathrm{p}=0.018)$ and high CRP levels $(\mathrm{OR}=2.99$, $95 \%$ CI $1.93-5.68, \mathrm{p}=0.018$ ) were significantly associated with the risk of developing EIMs (Table VI).

\section{DISCUSSION}

We analyzed a large Romanian cohort of IBD patients, included in the multicenter electronic database "IBD Prospect" Registry, where data and events are registered in a real-time manner. We performed a descriptive cross-sectional study, assessing the point prevalence of all EIMs, the frequency of different types of EIMs, as well as risk factors for developing EIMs, using univariate and multivariate analysis.
Out of 2,626 IBD patients included, 1,099 were CD patients (41.9\%), 1,484 had UC (56.5\%), and 43 had IBDU (1.6\%). The number of IBDU cases seems low as they were considered in relation to all IBD patients and not only to those with colitis. Additionally, it has been proved that less than 5\% of IBDU cases maintain this diagnosis over time [12], and we believe that at their initial diagnosis, more cases of colonic IBD were labeled as unclassified.

From the total number of 2,626 patients, 429 presented at least one EIM at the moment of the study, resulting in a global point prevalence of $16.3 \%$. Regarding phenotype, CD patients had a significantly higher prevalence of EIMs, compared to UC and IBDU patients $(\mathrm{p}<0.001)$. Previous data highlighted that IBD patients may experience EIMs in a largely variable proportion, between 6-47\%, depending on the study population, study type, definition criteria, and duration of 
Table IV. Predictive factors for EIMs in CD patients - multivariate analysis

\begin{tabular}{|c|c|c|c|c|c|}
\hline \multirow[t]{2}{*}{ Variable } & \multirow{2}{*}{$\begin{array}{c}\text { Odd ratio } \\
\operatorname{Exp}(\beta)\end{array}$} & \multicolumn{2}{|c|}{ 95\% CI for $\operatorname{Exp}(\mathrm{B})$} & \multirow[t]{2}{*}{ SE } & \multirow[t]{2}{*}{$\mathrm{p}$} \\
\hline & & Lower & Upper & & \\
\hline \multicolumn{6}{|l|}{ Gender } \\
\hline Male & Reference & & & & \\
\hline Female & 2.56 & 1.57 & 3.07 & 0.145 & $0.002^{*}$ \\
\hline Age & 1.01 & 0.98 & 1.02 & 0.008 & 0.673 \\
\hline \multicolumn{6}{|l|}{ Place of origin } \\
\hline Rural & Reference & & & & \\
\hline Urban & 1.69 & 0.46 & 6.19 & 0.160 & 0.423 \\
\hline \multicolumn{6}{|l|}{ Smoking } \\
\hline Non-smoker & Reference & & & & \\
\hline Ex-smoker & 1.73 & 0.97 & 3.57 & 0.154 & 0.083 \\
\hline Smoker & 1.42 & 0.76 & 2.64 & 0.317 & 0.271 \\
\hline \multicolumn{6}{|l|}{ Disease activity } \\
\hline Remission & Reference & & & & \\
\hline Mild activity & 1.38 & 0.90 & 2.09 & 0.213 & 0.130 \\
\hline Moderate activity & 1.84 & 1.57 & 2.14 & 0.202 & $0.041^{\star}$ \\
\hline Severe activity & 1.95 & 1.62 & 2.24 & 0.254 & $0.037^{\star}$ \\
\hline Elevated CRP & 1.13 & 0.51 & 2.52 & 0.408 & 0.759 \\
\hline $\mathrm{Hb}$ & 1.04 & 0.65 & 1.67 & 0.240 & 0.847 \\
\hline Serum albumin level & 1.11 & 0.66 & 1.87 & 0.264 & 0.683 \\
\hline \multicolumn{6}{|l|}{ Location } \\
\hline $\mathrm{L} 1$ & Reference & & & & \\
\hline $\mathrm{L} 2$ & 2.53 & 2.10 & 5.80 & 0.224 & $0.029^{*}$ \\
\hline L3 & 3.83 & 2.71 & 5.53 & 0.209 & $0.001^{*}$ \\
\hline Concomitant L4 & 4.90 & 2.27 & 5.96 & 0.290 & $0.021^{*}$ \\
\hline
\end{tabular}

${ }^{*}$ Marked effects are significant at $\mathrm{p}<0.05$; CI: confidence interval: SE: standard error; IBD: inflammatory bowel disease; CRP: C-reactive protein; Hb: Hemoglobin; L1: Ileal; L2: Ileocolonic; L4: Upper gastrointestinal tract.

follow-up [1-4]. Overall, it is estimated that one third of IBD patients develop EIMs [2]. In our study, we identified a lower rate of EIMs compared to the global estimation, partly due to the study type, which assessed the presence of EIMs at a certain point in time, and also to the fact that many EIMs are transient and the absence of one particular EIM at a certain moment in time does not exclude its previous or subsequent development. Our study showed a higher rate of EIMs among CD patients, compared to UC patients, similarly to the data published so far $[13,14]$.

The most frequent EIMs, both globally and for each IBD subtype, were the rheumatological manifestations $(12.1 \%$ of all IBD patients), namely peripheral arthritis $(8.3 \%$ of IBD patients) and, less frequently, axial arthropathy (3.8\% of IBD patients). Even if they both refer to joint involvement and are immune-mediated manifestations, they differ in their relationship with disease activity. Peripheral arthritis is associated with intestinal disease activity, following the clinical course of the IBD and usually improves with IBD treatment, while axial arthropathy evolves independently from the intestinal disease activity. In our study, we found that both peripheral arthritis ( $12.4 \%$ frequency in CD vs $5.3 \%$ in UC) and axial spondyloarthritis (5.8\% frequency in CD vs $2.4 \%$ in UC) were significantly associated with $\mathrm{CD}(\mathrm{p}<0.001)$. Our data regarding the frequency of these manifestations were in accordance with the results of other studies so far. Thus, peripheral arthralgia/arthritis usually affects $5 \%$ to $10 \%$ of patients with UC and $10 \%$ to $20 \%$ of patients with CD [4, 15]. Axial spondyloarthritis is less frequent than peripheral arthralgia/arthritis in patients with IBD, occurring in 3-5\% of patients, although frequency values of up to $25 \%$ have been reported [16, 17]. Moreover, in many studies, rheumatological manifestations are indeed the most frequent EIMs in IBD patients $[7,18]$, but no unanimous data concerning differences in prevalence between CD and UC patients were found. In a retrospective cohort study including 626 IBD patients, Malaty et al. [19] found an overall prevalence of joint manifestations of $17 \%$, with $7 \%$ prevalence of peripheral arthritis, slightly higher in CD than in UC patients. A similar high prevalence of peripheral arthritis among CD patients had been previously reported in a Swiss study [5], contrasting with another European study revealing a higher prevalence of peripheral arthritis in UC patients (6.1\%) compared to CD patients $(1.7 \%)$ [20]. A Southern European study, published in 2016, analyzing 1,860 Greek patients with IBD showed that joint manifestations were the most frequent, followed by dermatological EIMs [21]. The analysis of a large Taiwanese database (3,153 IBD patients) found peripheral arthropathy as the most common 
Table V. Predictive factors for EIMs in UC patients - multivariate analysis

\begin{tabular}{|c|c|c|c|c|c|}
\hline \multirow[t]{2}{*}{ Variable } & \multirow{2}{*}{$\begin{array}{c}\text { Odd ratio } \\
\operatorname{Exp}(\beta)\end{array}$} & \multicolumn{2}{|c|}{ 95\% CI for $\operatorname{Exp}(\mathrm{B})$} & \multirow[t]{2}{*}{ SE } & \multirow[t]{2}{*}{$\mathrm{p}$} \\
\hline & & Lower & Upper & & \\
\hline \multicolumn{6}{|l|}{ Gender } \\
\hline Male & Reference & & & & \\
\hline Female & 3.62 & 1.2 & 2.31 & $0.002^{*}$ & 0.167 \\
\hline Age & 1.01 & 0.99 & 1.02 & 0.412 & 0.005 \\
\hline Familial history of IBD & 1.32 & 0.50 & 3.49 & 0.570 & 0.494 \\
\hline \multicolumn{6}{|l|}{ Place of origin } \\
\hline Rural & Reference & & & & \\
\hline Urban & 1.17 & 0.57 & 2.37 & 0.174 & 0.362 \\
\hline \multicolumn{6}{|l|}{ Smoking } \\
\hline Non-smoker & Reference & & & 0.256 & \\
\hline Smoker & 0.98 & 0.37 & 2.59 & 0.268 & 0.495 \\
\hline Ex-smoker & 1.15 & 0.39 & 3.35 & 0.103 & 0.548 \\
\hline \multicolumn{6}{|l|}{ Active disease } \\
\hline Remission & Reference & & & & \\
\hline Mild activity & 1.11 & 1.14 & 1.53 & 0.727 & 0.262 \\
\hline Moderate activity & 2.90 & 1.30 & 2.85 & $0.011^{*}$ & 0.265 \\
\hline Severe activity & 2.54 & 1.34 & 2.85 & $0.008^{*}$ & 0.232 \\
\hline Elevated CRP & 1.49 & 0.74 & 3.02 & 0.262 & 0.358 \\
\hline $\mathrm{Hb}$ & 1.27 & 0.67 & 2.41 & 0.257 & 0.325 \\
\hline Serum albumin level & 1.92 & 0.57 & 6.48 & 0.293 & 0.621 \\
\hline \multicolumn{6}{|l|}{ Extent } \\
\hline E1 & Reference & & & & \\
\hline $\mathrm{E} 2$ & 1.43 & 0.818 & 2.51 & 0.209 & 0.286 \\
\hline E3 & 3.31 & 1.286 & 4.136 & $0.005^{*}$ & 0.298 \\
\hline
\end{tabular}

${ }^{*}$ Marked effects are significant at $\mathrm{p}<0.05$; CI: confidence interval; SE: standard error; IBD: inflammatory bowel disease; CRP: C-reactive protein; Hb: Hemoglobin; E1: Proctitis; E2: Left side colitis; E3: Extended colitis.

EIM, followed by ankylosing spondylitis [22]. A prospective Norwegian population-based study showed a cumulative prevalence of peripheral arthritis of $12 \%$ during a follow-up period of 6.1 years [23]. A recently published pediatric study also ranked joint complaints first ( $20 \%$ of all children), followed by aphthous stomatitis and dermatologic involvement [24].

A higher prevalence of joint involvement in $\mathrm{CD}$ patients draws attention to this IBD phenotype. Defining a profile for the patient at risk for developing such a type of joint manifestations is important either for treatment or early specific management, in collaboration with the rheumatologist whenever necessary.

Dermatological manifestations may occur in up to $15 \%$ of patients $[1,25]$. They are mainly represented by erythema nodosum with a frequency of $1.4 \%$ among IBD patients in our study, and pyoderma gangrenosum with a frequency of

Table VI. Predictive factors for EIMs in IBDU patients - multivariate analysis

\begin{tabular}{|c|c|c|c|c|c|}
\hline \multirow[t]{2}{*}{ Variable } & \multirow{2}{*}{$\begin{array}{c}\text { Odd ratio } \\
\operatorname{Exp}(\beta)\end{array}$} & \multicolumn{2}{|c|}{ 95\% CI for $\operatorname{Exp}(B)$} & \multirow[t]{2}{*}{ SE } & \multirow[t]{2}{*}{$\mathrm{p}$} \\
\hline & & Lower & Upper & & \\
\hline \multicolumn{6}{|l|}{ Gender } \\
\hline Male & Reference & & & & \\
\hline Female & 1.38 & 0.24 & 7.85 & 0.385 & 0.713 \\
\hline \multicolumn{6}{|l|}{ Place of origin } \\
\hline Rural & Reference & & & & \\
\hline Urban & 4.81 & 1.48 & 7.52 & 0.168 & $0.018^{*}$ \\
\hline $\mathrm{Hb}$ & 1.26 & 0.21 & 7.66 & 0.320 & 0.799 \\
\hline Serum albumin level & 1.33 & 0.09 & 19.38 & 0.365 & 0.832 \\
\hline CRP & 2.99 & 1.93 & 5.68 & 0.029 & $0.018^{*}$ \\
\hline
\end{tabular}

${ }^{*}$ Marked effects are significant at $\mathrm{p}<0.05$; CI: confidence interval; SE: standard error; Hb: Hemoglobin; CRP:

C-reactive protein. 
$0.7 \%$. Other types of skin involvement are much less frequent, and we did not find any cases in our analysis (e.g., erythema multiforme, epidermolysis bulossa acquista, or acute febrile neutrophilic dermatosis, also known as Sweet syndrome). The prevalence of skin manifestations in our analysis was lower than in usual reports, probably due to their transient character. Erythema nodosum is generally more frequent and is described more commonly in CD than in UC, with variable reported prevalence rates of $2 \%$ to $7.5 \%$ in CD and 0.9 to $4 \%$ for UC $[15,26,27]$. This predilection for CD was also shown in our analysis; erythema nodosum had a significantly higher point prevalence in CD compared to UC patients $(2.7 \%$ vs $0.4 \%$, respectively, $\mathrm{p}<0.001)$. Several studies showed other predictive factors for erythema nodosum such as: female gender, young age at diagnosis, and coexistence of another EIM [28, 29]. This dermatological manifestation correlates with IBD activity and usually responds to treatment of the underlying IBD. Pyoderma gangrenosum is less common but more dramatic and potentially debilitating. It is classically reported in $0.5-5 \%$ of patients with IBD, more commonly in UC than CD $[7,26]$. A very recent systematic review and meta-analysis published by States et al. [30] in 2020 showed that the incidence of pyoderma gangrenosum in individual studies ranged from 0.4 to $2.6 \%$, being associated with female gender, CD, erythema nodosum, and ocular EIM. Pyoderma gangrenosum does not appear to be correlated with intestinal activity; it may develop independently from the IBD stage or evolution, even before intestinal symptoms arise, during remission, or even after colectomy [31]. Nevertheless, even if it is usually managed successfully with combined topical therapy and general treatment of the underlying IBD, in some cases it may have a more severe course [32]. Pyoderma gangrenosum was previously reported as progressing from erythema nodosum lesions [33], which could partially account for the increased frequency of erythema nodosum compared to pyoderma gangrenosum.

Ophthalmological manifestations are another type of wellrecognized immune-related extraintestinal manifestations of IBD, with a reported prevalence of up to $13 \%$, more common in CD than in UC patients $[34,35]$. Uveitis and episcleritis, the most frequent complications, were found with a point prevalence of $1.03 \%$ in our analysis, less than generally reported in other studies. This finding can be explained by their shortterm evolution, similarly to dermatological manifestations. While previous studies had showed that episcleritis was more frequent [28], recent ones seem to counterbalance this tendency in favor of uveitis $[3,7]$. Earlier studies revealed that among CD patients, those with colonic involvement were considered to be more at risk to experience ocular complications compared to those with extracolonic location [31]. Eye involvement was considered to be mainly related to UC; however, in our study ophthalmological manifestations were significantly more frequent in IBDU cases $(p<0.001)$. Ocular pathology is usually managed and solved using topical treatment, in addition to the treatment of the underlying IBD. In some cases, ocular manifestations may precede intestinal symptoms, and may be nonspecific at presentation. Besides, some ophthalmological disorders may occur as complications of steroid therapy. If left untreated, ocular complications may progress, with irreversible invalidating consequences; therefore, special attention must be paid to all eye-related symptoms, at any time of the disease course.

Among hepatobiliary EIMs, primary sclerosing cholangitis has a reported prevalence of $5 \%$ and $2 \%$ in UC and, respectively, $\mathrm{CD}$ patients [36]. Yet, there are studies reporting a lower prevalence in UC, around $1.1 \%$ [37]. We found a point prevalence of $0.8 \%$ in our analysis, slightly higher for UC compared to $\mathrm{CD}$ patients. Even though it is a much less common EIM than others, it has a special significance if diagnosed early, considering the very high prevalence of UC in patients with primary sclerosing cholangitis [38]. Male patients are at a higher risk for developing primary sclerosing cholangitis [36]. Pericholangitis, which has historically comprised distinct cholestatic biochemical features, is nowadays more properly referred to as small-duct primary sclerosing cholangitis, and is part of the primary sclerosing cholangitis spectrum [39].

Renourinary manifestations may consist in nephrolithiasis (either calcium oxalate stones due to hyperoxaluria, or uric acid stones whose formation mechanism implies dehydration), obstructive uropathy with hydronephrosis, fistulae involving the urinary tract, and recurrent UTI. They are non-immune mediated EIMs, expressing either metabolic abnormalities (in the care of stones) or the loco-regional anatomical extension of the inflammatory and fibrotic process (as the fistulous and obstructive complications). The renal stones were the most frequent renourinary manifestation (1.9\%), followed by recurrent UTI; ureterohydronephrosis was the least frequent renal EIM, with significant understandable predilection for CD compared to UC patients $(0.64 \%$ vs $0.07 \%$, respectively, $\mathrm{p}=0.025$ ).

Amyloidosis is an extremely rare systemic but severe complication, reported so far with a $0.5 \%$ prevalence in IBD patients, with a predilection for $\mathrm{CD}$, as highlighted by a recent systematic review [40]. The prevalence of amyloidosis in our study was even lower $(0.04 \%)$, with only one reported case associated with CD.

Multiple concomitant EIMs may appear in IBD patients, with rates reported so far between 0.3 and $4.5 \%$ [26, 41]. In our study, multiple EIMs were noted in $2.9 \%$ of all IBD patients, the most common situation being the association of two EIMs, significantly more frequent in IBDU patients compared to $\mathrm{CD}$ and UC patients $(9.3 \%$ vs $4 \%$ and $1.3 \%, \mathrm{p}<0.001)$. In the study population, a single EIM was more frequently met among CD patients, $18.3 \%$ of all CD patients, compared to significantly lower proportions in UC and IBDU $(p<0.001)$. The combination of more than two EIMs was much less frequently identified, with a predilection for CD patients.

In our study, distinct independent or associated risk factors were identified using univariate and multivariate logistic regression analysis and, shaping potential susceptibility profiles for EIMs.

For CD patients, univariate analysis highlighted that female gender, urban place of origin, elevated CRP levels, low hemoglobin, low albumin, ileocolonic location and upper gastrointestinal tract involvement were significant independent risk factors for EIMs. In UC, significant independent risk factors for developing EIMs were: female gender, patients' urban area of origin, non-smoker status, elevated CRP levels, 
low hemoglobin and serum albumin levels, moderate and severe disease activity, and extensive colitis. Prior available data have shown that, overall, EIMs are more frequent in female IBD patients $[42,43]$, who seem likely to develop the majority of the most common EIMs, such as peripheral arthropathy, skin and ocular involvement. Male patients are more susceptible to less frequent EIMs, such as axial spondyloarthritis and primary sclerosing cholangitis $[17,36]$. Moreover, female gender is associated with more side-effects to biologic treatment, which explains the lower adherence rate to biologics among female patients $[44,45]$. The significant correlation found in our study between patients' urban place of origin and presence of EIMs may be partly justified by the fact that patients from urban areas are usually taken care of territorially, and our data comes from tertiary care centers, where generally selected difficult cases are managed. Nonetheless, urban living was identified as a significant environmental risk factor for CD and IBD in general, as proved by several studies as well as by a recent review of meta-analyses $[46,47]$. Furthermore, in our study, biochemical markers reflecting the disease activity and/or its consequences were found to be significant risk factors for EIMs. This may be explained by the inflammatory markers signaling either disease activity, the presence of another extraintestinal inflammatory manifestation, or both. It is known that many frequent immune-mediated EIMs evolve in parallel with intestinal activity, while others develop independently. A marker like hypoalbuminemia may witness pathological conditions favoring complications; low serum albumin concentration and vitamin $\mathrm{D}$ deficiency, which has already proved to be a risk factor for IBD, seem to be entangled [48]. Consequently, we can also state that poor nutritional status may represent a risk factor for EIMs. Ileocolonic location and upper gastrointestinal tract involvement were significantly associated in our study with the presence of EIMs in CD patients, while in UC patients, extensive colitis correlated with the risk of EIMs. Certain EIMs, including peripheral arthropathies, are more frequent in colonic CD $[1,15]$, while others are more common in small bowel CD $[5,49]$. Since we performed a global analysis, we could presume that our results reflect a cumulative risk of EIMs for CD with ileocolonic location. Moreover, upper gastrointestinal tract location involved a particular risk for EIMs among CD patients. Regarding UC, extensive colitis has been previously correlated with a higher prevalence of EIMs [50]. Moderate and severe disease activity were found to be independent risk factors for EIMs only in UC patients. This finding can be partly attributed to the parallel course of certain common EIMs with the intestinal activity (peripheral arthritis, episcleritis). Non-smoker status as an independent risk factor for EIMs in UC patients is consistent with data revealed by studies published so far regarding tobacco as a protective factor for UC development [51].

Concerning IBDU patients, male gender (in contrast to the other two main IBD phenotypes), urban place of origin and biochemical markers were independent predictive factors for EIMs development.

According to multivariate analysis, female CD patients with moderate or severe disease activity, with any other location than L1 were prone to EIMs, while the UC patient profile at risk for developing EIMs was represented by the female gender, with moderate or severe extensive colitis. As for IBDU, urban patients with high CRP levels are at increased risk for EIMs.

Susceptibility profiles were therefore configured, combining both demographic and clinical parameters, either nonmodifiable or dynamic. Taking into account that IBDs are chronic diseases, occurrence of EIMs negatively affect the patient's outcomes. One particular aspect that should also be considered when managing EIMs is heterogeneity in pathophysiology. The mechanisms underlying and supporting inflammation in EIMs can be mainly seen either as an extension of immune responses arisen in the intestine (due to molecular mimicry, T-cell trafficking and ectopic expression of gut-specific chemokines) or as independent inflammatory events, consequent to systemic changes in innate immunity, changes in the microbiome and a general shift toward a proinflammatory state. However, since the diverse mechanisms underlying and perpetuating inflammation in EIMs have yet to be clearly defined, the development of specific treatment strategies is further limited [52]. Currently, foreseeing the risk of IBD patients for developing EIMs could represent a first step taken to avoid this risk or at least to be better prepared for its consequences. Moreover, considering that some EIMs are related to an inflammatory process and other are metabolic consequences, optimizing further treatments is a challenge. Treatment of EIMs should be based on the severity of symptoms and their association with IBD activity, having as the primary aim to control symptoms and preserve mobility and function, thus improving the patients' quality of life and reducing disability [53].

The presence of EIMs increases the burden of the disease for the IBD patient, and a holistic therapeutic approach becomes mandatory. The treatment strategy should be tailored according both to the IBD features as well as to the type of EIM. For instance, certain types of EIMs do not correlate with disease activity and do not respond to the specific treatment of the underlying IBD. Moreover, gut selective agents do not represent an effective choice for patients with associated EIMs; in this regard, for example, a CD patient with concomitant EIMs may benefit from anti-tumor necrosis factor agents or interleukin-12/23 inhibitors rather than those based on antiintegrin antibodies which have intestinal selectivity [54]. Thus, early identification of patients at risk for EIMs occurrence could help individualize treatment algorithm and follow-up.

\section{CONCLUSIONS}

IBD patients, especially those with CD, experience EIMs in a significant proportion, the most frequent in the studied population being joint manifestations. Significant independent risk factors for EIMs found both for CD and UC were: female gender, patient's urban area of origin, anemia, hypoalbuminemia, high CRP. Significant independent IBD phenotype-related risk factors were: ileocolonic location and concomitant involvement of upper gastrointestinal tract for $\mathrm{CD}$, and non-smoker status and both moderate and severe disease activity for UC. Male gender was an independent risk factor for EIMs in IBDU, together with high CRP, low hemoglobin and low albumin levels. According to multivariate analysis, female CD patients presenting moderate or severe 
disease activity and disease location other than isolated ileal involvement, and female UC patients with moderate or severe extensive colitis were the most exposed IBD patients. Anticipating the vulnerability by identifying independent and associated predictive risk factors should therefore become a part of the IBD patient diagnostic work-up, in order to apply the most appropriate follow-up strategy and act in a timely manner to ensure a disease course as favorable as possible.

Conflicts of interest: None to declare.

Authors' contributions: A.Trifan conceived and designed the study. M.D., L.G. and C.G. had major contributions to the development of IBD Prospect database. A.M.S., I.G. and G.E.G.B. drafted the manuscript. M.C., A.C., A.Tanțău, R.Z., A.G. D.G., D.D. E.D., C.C.P. contributed to the acquisition of data. M.M. analyzed the data. M.M., A.Trifan and A.M.S. interpreted the data. C.S. revised the manuscript for important intellectual content. All authors revised the manuscript and accepted the final version to be published.

Acknowledgements: The authors would like to thank all the doctors involved in the development and updating of the IBD Prospect database.

Supplementary material: To access the supplementary material visit the online version of the J Gastrointestin Liver Dis at http://dx.doi. org/10.15403/jgld-3818

\section{REFERENCES}

1. Danese S, Semeraro S, Papa A, et al. Extraintestinal manifestations in inflammatory bowel disease. World J Gastroenterol 2005;11:7227-7236. doi:10.3748/wjg.v11.i46.7227

2. Larsen S, Bendtzen K, Nielsen OH. Extraintestinal manifestations of inflammatory bowel disease: epidemiology, diagnosis, and management. Ann Med 2010;42:97-114. doi:10.3109/07853890903559724

3. Yang BR, Choi NK, Kim MS, et al. Prevalence of extraintestinal manifestations in Korean inflammatory bowel disease patients. PLoS One 2018;13:e0200363. doi:10.1371/journal.pone.0200363

4. Veloso FT, Carvalho J, Magro F. Immune-related systemic manifestations of inflammatory bowel disease. A prospective study of 792 patients. J Clin Gastroenterol 1996;23:29-34. doi:10.1097/00004836-199607000-00009

5. Vavricka SR, Brun L, Ballabeni P, et al. Frequency and risk factors for extraintestinal manifestations in the Swiss inflammatory bowel disease cohort. Am J Gastroenterol 2011;106:110-119. doi:10.1038/ajg.2010.343

6. Mendoza JL, Lana R, Taxonera C, Alba C, Izquierdo S, DíazRubio M. Extraintestinal manifestations in inflammatory bowel disease:differences between Crohn's disease and ulcerative colitis. Med Clin (Barc) 2005;125:297-300. doi:10.1157/13078423

7. Isene R, Bernklev T, Høie O, et al; EC-IBD Study Group. Extraintestinal manifestations in Crohn's disease and ulcerative colitis:results from a prospective, population-based European inception cohort. Scand J Gastroenterol 2015;50:300-305. doi:10.3109/00365521.2014.991752

8. Silverberg MS, Satsangi J, Ahmad T, et al. Toward an integrated clinical, molecular and serological classification of inflammatory bowel disease: report of a Working Party of the 2005 Montreal World Congress of Gastroenterology. Can J Gastroenterol 2005;19 Suppl A:5A-36A doi:10.1155/2005/269076
9. Magro F, Gionchetti P, Eliakim R, et al; European Crohn's and Colitis Organisation (ECCO). Third European Evidence-based Consensus on Diagnosis and Management of Ulcerative Colitis. Part 1: Definitions, Diagnosis, Extra-intestinal Manifestations, Pregnancy, Cancer Surveillance, Surgery, and Ileo-anal Pouch Disorders. J Crohns Colitis 2017;11:649-667. doi:10.1093/ecco-jcc/jjx008

10. Best WR, Becktel JM, Singleton JW, Kern F Jr. Development of the Crohn's disease activity index. National Cooperative Crohn's Disease Study. Gastroenterology 1976;70:439-444.

11. Schroeder KW, Tremaine WJ, Ilstrup DM. Coated oral 5-aminosalicylic acid therapy for mildly to moderately active ulcerative colitis. A randomized study. N Engl J Med 1987;317:1625-1629. doi:10.1056/ NEJM198712243172603

12. Zhou N, Chen WX, Chen SH, Xu CF, Li YM. Inflammatory bowel disease unclassified. J Zhejiang Univ Sci B 2011;12:280-286. doi:10.1631/ jzus.B1000172

13. Ott C, Schölmerich J. Extraintestinal manifestations and complications in IBD. Nat Rev Gastroenterol Hepatol 2013;10:585-595. doi:10.1038/ nrgastro.2013.117

14. Vadstrup K, Alulis S, Borsi A, et al. Cost Burden of Crohn's Disease and Ulcerative Colitis in the 10-Year Period Before Diagnosis-A Danish Register-Based Study From 2003-2015. Inflamm Bowel Dis 2020;26:1377-1382. doi:10.1093/ibd/izz265

15. Orchard TR, Wordsworth BP, Jewell DP. Peripheral arthropathies in inflammatory bowel disease:Their articular distribution and natural history. Gut 1998;42:387-391. doi:10.1136/gut.42.3.387

16. Monsen U, Sorstad J, Hellers G, Johansson C. Extracolonic diagnoses in ulcerative colitis:an epidemiological study. Am J Gastroenterol 1990;85:711-716.

17. Smale S, Natt RS, Orchard TR, Russell AS, Bjarnason I. Inflammatory bowel disease and spondylarthropathy. Arthritis Rheum 2001;44:2728-2736. doi:10.1002/1529-0131(200112)44:12<2728::aid$\operatorname{art} 459>3.0 . \operatorname{co} ; 2-8$

18. Bourikas LA, Papadakis KA. Musculoskeletal manifestations of inflammatory bowel disease. Inflamm Bowel Dis 2009;15:1915-1924. doi:10.1002/ibd.20942

19. Malaty HM, Lo GH, Hou JK. Characterization and prevalence of spondyloarthritis and peripheral arthritis among patients with inflammatory bowel disease. Clin Exp Gastroenterol 2017;10:259-263. doi:10.2147/CEG.S136383

20. Salvarani C, Vlachonikolis IG, van der Heijde DM, et al; European Collaborative IBD Study Group. Musculoskeletal manifestations in a population-based cohort of inflammatory bowel disease patients. Scand J Gastroenterol 2001;36:1307-1313. doi:10.1080/003655201317097173

21. Karmiris K, Avgerinos A, Tavernaraki A, et al. Prevalence and Characteristics of Extra-intestinal Manifestations in a Large Cohort of Greek Patients with Inflammatory Bowel Disease. J Crohns Colitis 2016;10:429-436. doi:10.1093/ecco-jcc/jjv232

22. Hsu YC, Wu TC, Lo YC, Wang LS. Gastrointestinal complications and extraintestinal manifestations of inflammatory bowel disease in Taiwan: A population-based study. J Chin Med Assoc 2017;80:56-62. doi:10.1016/j.jcma.2016.08.009

23. Palm $\varnothing$, Moum B, Jahnsen J, Gran JT. The prevalence and incidence of peripheral arthritis in patients with inflammatory bowel disease, a prospective population-based study (the IBSEN study). Rheumatology (Oxford) 2001;40:1256-1261. doi:10.1093/rheumatology/40.11.1256

24. Cohen S, Padlipsky J, Yerushalmy-Feler A. Risk factors associated with extraintestinal manifestations in children with inflammatory bowe disease. Eur J Clin Nutr 2020;74:691-697. doi:10.1038/s41430-019-0490-1 
25. Farhi D, Cosnes J, Zizi N, et al. Significance of erythema nodosum and pyoderma gangrenosum in inflammatory bowel diseases: A cohort study of 2402 patients. Medicine (Baltimore) 2008;87:281-293. doi:10.1097/ MD.0b013e318187cc9c

26. Lakatos L, Pandur T, David G, et al. Association of extraintestinal manifestations of inflammatory bowel disease in a province of western Hungary with disease phenotype: results of a 25-year follow-up study. World J Gastroenterol 2003;9:2300-2307. doi:10.3748/wjg.v9.i10.2300

27. Lindgren A, Wallerstedt S, Olsson R. Prevalence of Crohn's disease and simultaneous occurrence of extraintestinal complications and cancer. An epidemiologic study in adults. Scand J Gastroenterol 1996;31:74-78. doi:10.3109/00365529609031630

28. Veloso FT. Extraintestinal manifestations of inflammatory bowel disease do they influence treatment and outcome? World J Gastroenterol 2011;17:2702-2707. doi:10.3748/wjg.v17.i22.2702

29. Ampuero J, Rojas-Feria M, Castro-Fernández M, Cano C, RomeroGómez M. Predictive factors for erythema nodosum and pyoderma gangrenosum in inflammatory bowel disease. J Gastroenterol Hepatol 2014;29:291-295. doi:10.1111/jgh.12352

30. States V, O’Brien S, Rai JP, et al. Pyoderma Gangrenosum in Inflammatory Bowel Disease: A Systematic Review and MetaAnalysis. Dig Dis Sci 2020;65:2675-2685. doi:10.1007/s10620-01905999-4

31. Jose FA, Heyman MB. Extraintestinal manifestations of inflammatory bowel disease. J Pediatr Gastroenterol Nutr 2008;46:124-133. doi:10.1097/MPG.0b013e318093f4b0

32. Barrie A, Plevy S. Treatment of immune-mediated extraintestinal manifestations of inflammatory bowel disease with infliximab. Gastroenterol Clin North Am 2006;35:883-893. doi:10.1016/j. gtc.2006.09.001

33. Gellert A, Green ES, Beck ER, Ridley CM. Erythema nodosum progressing to pyoderma gangrenosum as a complication of Crohn's disease. Postgrad Med J 1983;59:791-793. doi:10.1136/pgmj.59.698.791

34. Vavricka SR, Rogler G, Gantenbein C, et al. Chronological Order of Appearance of Extraintestinal Manifestations Relative to the Time of IBD Diagnosis in the Swiss Inflammatory Bowel Disease Cohort. Inflamm Bowel Dis 2015;21:1794-1800. doi:10.1097/ MIB.0000000000000429

35. Evans PE, Pardi DS. Extraintestinal manifestations of inflammatory bowel disease:focus on the musculoskeletal, dermatologic, and ocular manifestations. MedGenMed 2007;9:55

36. Lee YM, Kaplan MM. Primary sclerosing cholangitis. N Engl J Med 1995;332:924-933. doi:10.1056/NEJM199504063321406

37. Ye BD, Yang SK, Boo SJ, et al. Clinical characteristics of ulcerative colitis associated with primary sclerosing cholangitis in Korea. Inflamm Bowel Dis 2011;17:1901-1906. doi:10.1002/ibd.21569

38. Broomé U, Bergquist A. Primary sclerosing cholangitis, inflammatory bowel disease, and colon cancer. Semin Liver Dis 2006;2:31-41. doi:10.1055/s-2006-933561

39. Karlsen TH, Boberg KM. Update on primary sclerosing cholangitis. J Hepatol 2013;59:571-582. doi:10.1016/j.jhep.2013.03.015

40. Tosca Cuquerella J, Bosca-Watts MM, Anton Ausejo R, Tejedor Alonso S, Mora De Miguel F, Minguez Perez M. Amyloidosis in Inflammatory
Bowel Disease:A Systematic Review of Epidemiology, Clinical Features, and Treatment. J Crohns Colitis 2016;10:1245-1253. doi:10.1093/eccojcc/jjw080

41. Bernstein CN, Blanchard JF, Rawsthorne P, Yu N. The prevalence of extraintestinal diseases in inflammatory bowel disease: a populationbased study. Am J Gastroenterol 2001;96:1116-1122. doi:10.1111/j.15720241.2001.03756.x

42. Greuter T, Manser C, Pittet V, Vavricka SR, Biedermann L; on behalf of Swiss IBDnet, an official working group of the Swiss Society of Gastroenterology. Gender Differences in Inflammatory Bowel Disease. Digestion 2020;101 Suppl 1:98-104. doi:10.1159/000504701

43. Severs M, Spekhorst LM, Mangen MJ, et al. Sex-Related Differences in Patients With Inflammatory Bowel Disease: Results of 2 Prospective Cohort Studies. Inflamm Bowel Dis 2018;24:1298-1306. doi:10.1093/ $\mathrm{ibd} / \mathrm{izy} 004$

44. Lie MR, Kreijne JE, van der Woude CJ. Sex Is Associated with Adalimumab Side Effects and Drug Survival in Patients with Crohn's Disease. Inflamm Bowel Dis 2017;23:75-81. doi:10.1097/ MIB.0000000000000981

45. Mazor Y, Maza I, Kaufman E, et al. Prediction of disease complication occurrence in Crohn's disease using phenotype and genotype parameters at diagnosis. J Crohns Colitis 2011;5:592-597. doi:10.1016/j. crohns.2011.06.002

46. Piovani D, Danese S, Peyrin-Biroulet L, Nikolopoulos GK, Lytras T, Bonovas S. Environmental Risk Factors for Inflammatory Bowel Diseases: An Umbrella Review of Meta-analyses. Gastroenterology 2019;157:647-659.e4. doi:10.1053/j.gastro.2019.04.016

47. Ng SC, Tang W, Leong RW, et al; Asia-Pacific Crohn's and Colitis Epidemiology Study ACCESS Group. Environmental risk factors in inflammatory bowel disease:a population-based case-control study in Asia-Pacific. Gut 2015;64:1063-1071. doi:10.1136/gutjnl-2014-307410

48. Del Pinto R, Pietropaoli D, Chandar AK, Ferri C, Cominelli F. Association Between Inflammatory Bowel Disease and Vitamin D Deficiency: A Systematic Review and Meta-analysis. Inflamm Bowel Dis 2015;21:2708-2717. doi:10.1097/MIB.0000000000000546

49. Levine JS, Burakoff R. Extraintestinal manifestations of inflammatory bowel disease. Gastroenterol Hepatol (N Y) 2011;7:235-241.

50. Weiss A, Mayer L. Extraintestinal manifestations of inflammatory bowel disease. In: Allan RN, Rhodes JM, Hanauer SB. (Eds.). Inflammatory bowel diseases. Churchill Livingstone, New York 1997:623-636.

51. Mahid SS, Minor KS, Soto RE, Hornung CA, Galandiuk S. Smoking and inflammatory bowel disease:a meta-analysis. Mayo Clin Proc 2006;81:1462-1471. doi:10.4065/81.11.1462

52. Greuter T, Rieder F, Kucharzik T, et al. Emerging treatment options for extraintestinal manifestations in IBD. Gut 2021;70:796-802. doi:10.1136/gutjnl-2020-322129

53. Kim JM, Cheon JH. Pathogenesis and clinical perspectives of extraintestinal manifestations in inflammatory bowel diseases. Intest Res 2020;18:249-264. doi:10.5217/ir.2019.00128

54. Shim HH, Chan PW, Chuah SW, Schwender BJ, Kong SC, Ling KL. A review of vedolizumab and ustekinumab for the treatment of inflammatory bowel diseases. JGH Open 2018;2:223-234. doi:10.1002/ jgh3.12065 